\title{
Observational Study of Acute Kidney Injury in Patients of Falciparum and Vivax Malaria in India
}

\author{
Prashant S.Hiwale, P.K.Mukherjee \\ Department of General Medicine, Deben Mahato Hospital and Government Medical College \\ DOI: 10.29322/IJSRP.11.12.2021.p12018 \\ http://dx.doi.org/10.29322/IJSRP.11.12.2021.p12018
}

\begin{abstract}
Background: Plasmodium falciparum malaria is known to cause serious complication like acute kidney injury (AKI) but now a days Plasmodium vivax malaria is not rare to cause this complication. Many recent reports have shown that P. vivax malaria is also responsible for AKI. There is paucity of data from this region on the profile of AKI in patients of $\mathrm{P}$. falciparum and P. vivax malaria.
\end{abstract}

Objective: To observe demographic profile, clinical features, mortality indicators, need for dialysis and outcome in patients of P. falciparum and P. vivax malaria.

Material and methods: A prospective observational study was conducted in the Department of General Medicine, Deben Mahato Hospital and Government Medical College, Purulia from July 2017 to June 2018 among diagnosed patients of malaria with evidence of AKI. Diagnosis of malaria was confirmed by thick and thin peripheral smear stained with Leishman's stain and rapid malarial antigen test. Appropriate statistical analysis was done to study various parameters.

Result: There were $43(21.5 \%)$ cases of AKI due to P. falciparum and $58(25.9 \%)$ cases of AKI due to P. vivax malaria, out of 200 cases of $\mathrm{P}$. falciparum and 220 cases of $\mathrm{P}$. vivax malaria. Most patients in both groups were less than 30 years of age. Females were affected more commonly in both groups. Pallor, hypotension, oliguria, sepsis and altered sensorium were common in P. falciparum malaria. Jaundice, vomiting, thrombocytopenia, hepatomegaly and splenomegaly were more common in P. vivax malaria. Oliguria, anaemia, acute respiratory distress syndrome (ARDS), Disseminated intravascular coagulopathy (DIC), cerebral malaria, hypotension, hyponatraemia, hyperbilirubinaemia were commonly associated independent risk factors for mortality in both $\quad P$. falciparum and P. vivax malaria. P. falciparum and P. vivax malaria patients received antimalarial artesunate combination therapy. $13(30.23 \%)$ cases of P. falciparum and $17(29.31 \%)$ cases of P. vivax underwent haemodialysis. 5 (11.62\%) patients of P. falciparum malaria and 9 (15.52\%) patients of P. vivax malaria AKI died.

Index Terms- Acute kidney injury, Anuria, Cerebral malaria, P. falciparum and P. vivax malaria

\section{INTRODUCTION}

$\mathrm{M}$ alaria is a common public health problem in India and contributes to significant mortality and morbidity. There were an estimated 214 million new cases of malaria and 4.38 lakhs deaths in the year 2015 globally $^{1}$. In India, estimated cases of malaria in 2014 were 1.4 million with 561 deaths ${ }^{1}$. Most cases occurred in the African region (88\%) followed by the South East Asia region (10\%) and Eastern Mediterranean region (2\%). In South East Asia, India has the highest burden of malaria ${ }^{2}$. Half of the total malaria cases in India were reported from Chhattisgarh, Orissa, Jharkhand, Madhya Pradesh and West Bengal ${ }^{3}$. Recently, a changing trend has been observed not only in clinical manifestations but also the pattern of complications in malaria. Over a decade ago, the main manifestation was cerebral malaria but now a days a combination of liver dysfunction and renal failure is more common ${ }^{7}$. Acute Kidney injury (AKI) is one of the dreaded complications of malaria. Renal dysfunction occurs more commonly in $P$. falciparum malaria, although not uncommon with P. vivax malaria ${ }^{4,5,6}$.

The prevalence of AKI in malaria all over the world has been reported from $0.57 \%$ to $60 \%{ }^{8-11}$. Such a wide variation may occur due to differences in diagnostic criteria to define AKI and characteristics of the study population. Established AKI in malaria is usually oliguric and hypercatabolic, which may last for days to weeks, although urine output may also be normal even with a rising trend of serum creatinine level ${ }^{12}$.

\section{MATERIAL AND METHODS}

The present study was a hospital based prospective observational study conducted in the Department of General Medicine, Deben Mahato Hospital and Government Medical College, Purulia The duration of the study was from July 2017 to June 2018 among patients admitted in the Medicine ward. All cases of fever, suspected to have malaria, were evaluated by thick and thin peripheral smear stained with Leishman's stain for malarial parasite and rapid malarial antigen test. A total of 200 patients of $P$. falciparum and 220 patients of $P$. vivax malaria were recruited in the study. We excluded those patients who were not willing for study, patients with mixed malarial infection, pregnant females, age $<14$ years and having any evidence of chronic kidney disease by clinical, laboratory and imaging study.

After detailed history, patients were subjected to clinical examination. Renal function tests including blood urea and creatinine, complete blood count, liver function test, serum electrolytes, serum lactate dehydrogenase (LDH), urine analysis, plasma blood sugar, coagulation profile for disseminated intravascular coagulation, chest $\mathrm{X}$-ray and renal ultrasonography. $\mathrm{HIV}, \mathrm{HbsAg}$, anti-HCV and serum leptospira antibody were done when indicated. All proven cases were treated with parenteral artesunate combination therapy followed by oral artesunate 
combination therapy as per WHO guidelines ${ }^{13,14}$. Renal replacement therapy was given in the form of intermittent haemodialysis when indicated. Patients were followed until discharge or death. AKI was defined as sudden rise in serum creatinine $>2 \mathrm{mg} / \mathrm{dl}$ in a previously healthy person, or decline in urine output $\quad<400 \mathrm{ml} /$ day or both ${ }^{15}$.

\section{STATISTICAL ANALYSIS}

The statistical analysis was carried out using statistical software SPSS Version 16.0 for windows. The difference in proportions was compared by Chi-square test. The critical value of ' $p$ ' indicating the probability of significant difference was taken as less than $0.05 \mathrm{f}$ or comparison.

\section{RESULT}

A total of 200 patients of $P$. falciparum and 220 patients of P. vivax malaria were studied between July 2017 to June 2018, $43(21.5 \%)$ (14 male and 29 female) patients of $\quad$ P. falciparum and $58(25.9 \%$ ) (20 male and 38 female) patient of $\mathrm{P}$. vivax malaria developed acute kidney injury. This data suggests that females more commonly developed AKI. AKI was also more common in younger age group as shown in Table I.

Clinical profile of P.falciparum and P.vivax malaria associated AKI is shown in Table II. Fever, hypotension, oliguria, sepsis and altered sensorium were more commonly observed clinical features in $100 \%, 48.83 \%, 53.48 \%, 23.25 \%$ and $11.62 \%$ cases of P. falciparum malaria, respectively, associated with AKI. Fever, jaundice, thrombocytopenia,

hepatomegaly and splenomegaly were more commonly observed clinical features in $100 \%, 60.34 \%, 77.58 \%, 50 \%$ and $58.62 \%$ cases, respectively, in P.vivax malaria associated with AKI.The contributing factors causing AKI are shown in Table III. Renal manifestations in patients of $\mathrm{P}$. falciparum and P. vivax malaria associated with AKI are shown in TableIV. Oliguria (53.48\%), uraemic encephalopathy $(6.97 \%)$, metabolic acidosis $(16.27 \%)$ were more common renal manifestations observed in P. falciparum associated AKI.

Table I: Demographic profile of P. falciparum and P.vivax associated AKI.

\begin{tabular}{|c|c|c|}
\hline & P. falciparum P. vivax & P. vivax \\
\hline $\begin{array}{l}\text { No. of mal } \\
\text { patients }\end{array}$ & iial200 & 220 \\
\hline \multicolumn{2}{|c|}{ No. of AKI patients43 (21.5\%) } & $58(25.9 \%)$ \\
\hline $\begin{array}{l}\text { Age (Years) } \\
30\end{array}$ & $<25(58.1 \%)$ & $31(53.44 \%) p=0.843$ \\
\hline $31-45$ & $9(20.94 \%)$ & $13(22.41 \%) \mathrm{NS}$ \\
\hline $36-60$ & $5(11.62 \%)$ & $10(17.24 \%)$ \\
\hline$>60$ & $4(9.3 \%)$ & $4(6.89 \%)$ \\
\hline Male & $14(32.55 \%)$ & $20(34.48 \%)>0.999$ \\
\hline Female & $29(67.44 \%)$ & $38(65.51 \%) \mathrm{NS}$ \\
\hline
\end{tabular}

NS = Not significant

Table II: Clinical features of P. falciparum and P. vivax malaria associated AKI.

\begin{tabular}{llll}
\hline $\begin{array}{l}\text { S.No Clinical features } \\
\text { - }\end{array}$ & P. falciparum & P. vivax \\
\hline 1. & Fever & AKI $(\mathbf{n}=\mathbf{4 3 )}$ & AKI $(\mathbf{n}=\mathbf{5 8})$ \\
\hline 2. & Jaundice & $43(100 \%)$ & $58(100 \%)$ \\
\hline 3. & Anaemia & $21(48.83 \%)$ & $35(60.34 \%)$ \\
\hline 4. & Hypotension & $21(48.33 \%)$ & $35(60.34 \%)$ \\
\hline 5. & Intravascular & $23(53.48 \%)$ & $29(50 \%)$ \\
\hline 6. & Nausea and vomiting & $42(97.67 \%)$ & $56(96.55 \%)$ \\
\hline 7. & Thrombocytopenia & $21(48.03 \%)$ & $45(77.58 \%)$ \\
\hline 8. & Hepatomegaly & $16(37.20 \%)$ & $29(50 \%)$ \\
\hline 9. & Splenomegaly & $19(44.18 \%)$ & $34(58.62 \%)$ \\
\hline & & & \\
\hline
\end{tabular}




\begin{tabular}{|c|c|c|}
\hline 10. Oliguria & $23(53.48 \%)$ & $26(44.82 \%)$ \\
\hline 11. Sepsis & $10(23.25 \%)$ & $7(12.06 \%)$ \\
\hline 12. Altered sensorium & $5(11.62 \%)$ & $4(6.89 \%)$ \\
\hline 13. ARDS & $3(6.97 \%)$ & $5(8.62 \%)$ \\
\hline
\end{tabular}

The mortality indicators in patients of P. falciparum and P. vivax malaria associated with AKI are shown in Table V. Oliguria, anaemia, ARDS, DIC, cerebral malaria, hypotension, hyponatraemia, hyperbilirubinaemia were independent risk factors for high mortality among patients of P. falciparum malaria. Oliguria, anaemia, hypotension, hyperbilirubinaemia, ARDS, hyponatraemia were independent risk factors for high mortality among patients of P.vivax malaria.

Table III: Possible etiological factors causing AKI in P. falciparum and P. vivax

\begin{tabular}{|c|c|}
\hline S. No. Clinical features & $\begin{array}{lc}\text { P. falciparum } & \text { P. vivax } \quad p \text {-value } \\
\operatorname{AKI}(n=43) & \operatorname{AKI}(n=58)\end{array}$ \\
\hline $\begin{array}{l}\text { 1. Heavy } \\
\text { Parasitaemia }\end{array}$ & $25(58.13 \%) 28(48.27 \%) \mathrm{NS}$ \\
\hline Hypotension & $21(48.83 \%) 15(25.86 \%)$ \\
\hline Sepsis & $10(23.25 \%) 7(12.06 \%)$ \\
\hline $\begin{array}{l}4 . \\
\text { haemolysis }\end{array}$ & $23(53.48 \%) 29(50 \%)$ \\
\hline Hyperbilirubina & $21(48.83 \%) 35(60.34 \%)$ \\
\hline DIC & $17(39.53 \%) 17(29.31 \%)$ \\
\hline
\end{tabular}

NS - Not significant.

Table IV: Renal manifestations of P. falciparum and P. vivax malaria associated AKI.

\section{S. No. Clinical features P. falciparum $\quad P$. vivax $p$ - value $\operatorname{AKI}(\mathbf{n}=43) \quad$ AKI $(n=58)$}

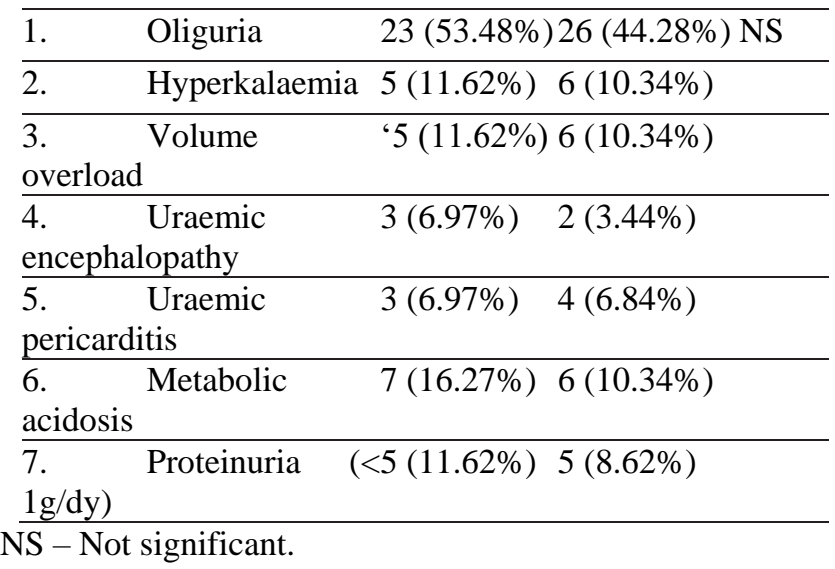


Table V: Mortality Indicators of P. falciparum and P. vivax associated AKI.

\begin{tabular}{|c|c|c|c|c|}
\hline \multirow{2}{*}{$\begin{array}{l}\text { S. Parameters } \\
\text { N } \\
\text { o. }\end{array}$} & \multicolumn{2}{|c|}{$\begin{array}{l}\text { P. falciparum } \\
\text { AKI }(n=43)\end{array}$} & \multicolumn{2}{|c|}{$\begin{array}{l}\text { P. vivax } \\
\text { AKI }(n=58)\end{array}$} \\
\hline & $\begin{array}{l}\text { Survived } \\
(\mathrm{n}=38)\end{array}$ & $\begin{array}{l}\text { Expired } \\
(\mathrm{n}=5)\end{array}$ & $\begin{array}{l}\text { Survived } \\
(\mathrm{n}=49)\end{array}$ & \\
\hline $\begin{array}{l}\text { Oliq } \\
\text { on a }\end{array}$ & & $4(80 \%)$ & $19(38.7 \%)$ & $\begin{array}{l}7 \\
(77.7 \%)\end{array}$ \\
\hline 2. Hypot & $19(50 \%)$ & $2(40 \%)$ & $10(20.4 \%)$ & $\begin{array}{l}5 \\
(55.5 \%)\end{array}$ \\
\hline $\begin{array}{l}\text { Met } \\
\text { acid }\end{array}$ & 601 & $\%$ & $4(8$ & \\
\hline $\begin{array}{l}\text { Hypc } \\
\text { a }\end{array}$ & $\begin{array}{l}13 \\
(34.2 \%)\end{array}$ & $2(40 \%)$ & 14 & $\begin{array}{l}3 \\
(3 .\end{array}$ \\
\hline $\begin{array}{l}\text { Hyp } \\
\text { aemi }\end{array}$ & 19 & $2(40 \%)$ & 30( & $\begin{array}{l}5 \\
(55.5 \%) \\
\end{array}$ \\
\hline 6. An & $\begin{array}{l}18 \\
(47.4 \%)\end{array}$ & $3(60 \%)$ & $29(59.1 \%)$ & $\begin{array}{l}6 \\
(66.7 \%) \\
\end{array}$ \\
\hline 7. ARD & Nil & $3(60 \%)$ & $1(2.04 \%)$ & $\begin{array}{l}4 \\
(44.4 \%)\end{array}$ \\
\hline 8 DIC & $\begin{array}{l}14 \\
(36.8 \%)\end{array}$ & $(60 \%)$ & $.6 \%)$ & $\begin{array}{l}2 \\
(22.2 \%)\end{array}$ \\
\hline $\begin{array}{l}\text { Cere } \\
\text { mala }\end{array}$ & $2(5.26 \%)$ & $3(60 \%)$ & $2(4.08 \%)$ & $\begin{array}{l}2 \\
(22.2 \%) \\
\end{array}$ \\
\hline Iyperkalaem & $4(10.5 \%)$ & $1(20 \%)$ & 6\%) & \\
\hline
\end{tabular}

Table VI: Outcome of $P$. falciparum and $P$. vivax malaria associated AKI.

\begin{tabular}{|c|c|c|}
\hline \multicolumn{2}{|c|}{ S. No. Outcome P. falciparum } & \multirow{2}{*}{$\begin{array}{c}\text { P. Vivax } \\
(29.3 \%) \\
\text { NS }\end{array}$} \\
\hline $\begin{array}{l}1 . \quad \text { Dialysis } \\
\text { requirement }\end{array}$ & $13(30.23 \%) 17$ & \\
\hline $\begin{array}{l}2 . \quad \text { Sessions } \\
\text { dialysis (days) }\end{array}$ & \multicolumn{2}{|c|}{ of $3.85 \pm 1.52 \quad 4.24 \pm 1.68$} \\
\hline $\begin{array}{ll}3 . & \text { Length } \\
\text { (days) } & \end{array}$ & of stay7.69 \pm 3.048 .1 & \pm 3.81 \\
\hline $\begin{array}{l}. \quad \text { In } \\
\text { mortality }\end{array}$ & hospital5 (11.62\%) 9 & $2 \%)$ \\
\hline
\end{tabular}

\section{DISCUSSION}

A total of 200 patients of P. falciparum and 220 patients of P. vivax malaria were included in the study. There were 43 (21.5\%) cases of P. falciparum and $58(25.9 \%)$ cases of P. vivax malaria with AKI. Singh et al16 reported AKI in 5.6\% of P. vivax and $6.1 \%$ of $P$. falciparum malaria.

In our study, maximum patients were less than 30 years of age due to unknown reason which is similar to previous study ${ }^{4}$. In a study by Naqvi et $\mathrm{al}^{8}$ male to female ratio was $4: 1$ but in our study, male to female ratio were $1: 2$ in P. falciparum and 1:1.9 in P. vivax malaria.
Mechanical obstruction caused by cytoadherance and sequestration of infected red blood cells to the vascular endothelial cells of different host organs along with rosette formation is the most considered pathogenesis of AKI in malaria ${ }^{17,18,19}$. Immune mediated glomerular pathology, release of cytokines, reactive oxygen intermediates and nitric oxides by activated mononuclear cells, alterations in renal and systemic haemodynamics have been proposed mechanisms of AKI in P. falciparum malaria. However, aetiology of renal damage in $P$. vivax malaria still remains unclear. Thrombotic microangiopathy and haemolytic ureamic syndrome associated with P.vivax indicate AKI in some situations, P. vivax malaria causes microvascular thrombosis, endothelial injury and thrombocytopenia almost identical to thrombotic thrombocytopenia purpura ${ }^{20,21}$. Cause of AKI in malaria whether prerenal, renal (acute tubular necrosis, acute glomerulonephritis, 
acute interstitial nephritis, acute cortical necrosis) could not be specified because renal biopsy could not be done as consent was not given by the patients. Other contributory causes of AKI include MODS/sepsis, hypotension, hyperbilirubinaemia, etc.

In addition to the above, decreased blood flow to the kidneys due to low intake of fluid, loss of fluids due to vomiting and pyrexial sweating can cause dehydration and renal ischaemia ${ }^{12}$. Nausea and vomiting was present almost in all cases of malaria associated with AKI.

In our study, thrombocytopenia was more common in $\mathrm{P}$. vivax as compared to $\mathrm{P}$. falciparum malaria $(77.58 \%$ vs $48.83 \%$ ). Prakash et al reported thrombocytopenia as $10.5 \%$ in P. vivax malaria ${ }^{5}$

Anaemia was present in $48.83 \%$ of P.falciparum and $60.34 \%$ of P. vivax malaria cases. Anaemia occurs in malaria due to haemolysis of parasitized red blood cells, splenic hyperactivity, and/or bone marrow suppression. Shukla et al reported anaemia in $69 \%$ of malarial associated $\mathrm{AKI}^{22}$. Hepatic dysfunction was a common complication, apart from acute kidney injury in our study, which is almost identical to the reported observations in P.falciparum and P.vivax malaria ${ }^{23,24}$. Presence of increased bilirubin level in malaria can act as a predisposing factor for AKI. Naqvi et al have reported that all patients of malarial AKI with jaundice had conjugated hyperbilirubinaemia with cholestasis $^{8}$. This well described association may contribute to the reduction of glomerular filtration rate or development of acute tubular necrosis ${ }^{4,11}$. Combination of AKI and jaundice in malaria had high mortality in comparison to those who did not have jaundice. Kaushik et al reported that $41 \%$ cases of malarial AKI had hyperbilirubinaemia ${ }^{25}$. In our study, hyperbilirubinaemia was present among $48.83 \%$ cases of P. falciparum, and $60.34 \%$ cases of P. vivax malaria, respectively.

Classical laboratory finding in malarial AKI of hyponatraemia has been reported in upto $69 \%$ cases of severe malaria $^{26}$. In our study, hyponatraemia was present in $34.88 \%$ cases of $P$. falciparum and $29.35 \%$ cases of $P$. vivax malaria. Hyponatraemia may occur due to the syndrome of inappropriate antidiuretic hormone secretion in response to hypovolaemia and cerebral salt wasting.

Khan et al, reported that dialysis was required in $78 \%$ of malarial $\mathrm{AKI}^{27}$.In our study, dialysis was required by $30.23 \%$ cases of $P$. falciparum and $29.3 \%$ cases of $P$. vivax malaria. Mortality in malarial AKI has been reported to be $21-37.9 \%$ from different parts of world ${ }^{8,28,29}$. In our study, mortality in malarial AKI was $11.62 \%$ among cases of P. falciparum and $15.52 \%$ among P.vivax malaria. Shukla et al ${ }^{22}$ reported $9.9 \%$ mortality in malarial AKI, which is comparable to our study.

Oliguria, hypotension, metabolic acidosis, hyponatraemia, hyperbilirubinaemia, anaemia, ARDS, DIC, cerebral malaria were noted as independent risk factors for mortality. Mortality increased with an increasing number of complications. ARDS was the most serious complication associated with mortality in our patients. Rising trend of serum creatinine, anuria, refractory metabolic acidosis, refractory hyperkalaemia, uraemic pericarditis and uraemic encephalopathy were indications for renal replacement therapy. Serum creatinine level significantly decreased after three sessions of haemodialysis. Most of our patients required 3 - 5 sessions of haemodialysis. Prognosis of malarial AKI depends on severity of non-renal complications.
Early initiation of haemodialysis along with antimalarial therapy has been shown to improve outcome. However, effective dialysis or ultrafiltration might further reduce mortality rate $^{30}$. Although peritoneal dialysis has been used in the treatment of malarial AKI but its success in severe cases is limited because of peritoneal dysfunction and low clearance due to microcirculation ${ }^{31}$. In our study, haemodialysis continued until kidney function improved in the form of increase in urine output or progressive decline in serum creatinine level

\section{CONCLUSION}

AKI is a frequent complication of $\mathrm{P}$. falciparum malaria and $P$. vivax malaria. Therefore, our study highlights the importance of P. vivax malaria associated AKI. Early recognition and timely initiation of renal replacement therapy along with antimalarial drugs may improve outcome of malarial AKI.

\section{ACKNOWLEDGMENT}

We express our gratitude towards our patients, central laboratory people who help us to complete this study.

\section{REFERENCES}

[1] World Malaria Report, 2015, Geneva Switzerland: WHO press: 2015.

[2] Word Health Organisation, Word Malaria Report fact sheet, 2012. Available at: http:/www.who.int Accessed 5 August 2013.

[3] Basu S, Gupta P. Malaria. In: Ghai OP, Gupta P, editors Text book of social and preventive medicine. 3rd ed. New Delhi: CBS Publisher and distribution 2010; 214-30.

[4] Barosum RS, Sitprija V. Tropical Nephrology. In: Schrier RW, Gottaschalk $\mathrm{CW}$, eds. Diseases of the kidney.VI ed. Boston MA: Little Brown \& Co.; 1996; 2221-68.

[5] Prakash J, Singh AK, Kumar NS et al. Acute renal failure in

[6] Plasmodium vivax malaria. J Assoc Phys India 2003; 51: 265-7.

[7] Trampuz A, Jereb M, Muzlovic I et al. Clinical review: Severe malaria.

[8] Crit Care 2003; 7: 315-23.

[9] Nand N, Agarwal H, Sharma M et al. Systemic manifestations in malaria. J Indian Acad Clin Med 2001; 2: 189-94.

[10] Naqvi R, Ahmed E, Akhtar F et al. Outcome in severe acute renal failure associated with malaria. Nephrol Dial Transplant 2003; 18 (9): 1820-3.

[11] Boonpucknavig V, Sitprija V. Renal disease in acute plasmodium falciparum infection in man. Kidney Int 1979; 16: 44-52.

[12] Singh N, Shukla MM, Sharma VP. Epidemiology of malaria in pregnancy in central India. Bull World Health Organ 1999; 77: 567-72.

[13] Mehta KS, Halankar AR, Makwanna PD et al. Severe acute renal failure in malaria. J Postgrad Med 2001; 47: 24-6.

[14] Das BS. Renal failure in malaria. J Vector Borne Dis 2008; 45 (2): 83-97.

[15] Manan JA, Ali H, Lal M. Acute renal failure associated with malaria.

[16] J Ayub Med Coll Abbottabad 2006; 18: 47-52.

[17] World Health Organisation: Guidelines for treatment of malaria. Geneva. World Health Organisation, 2006. Available at: http:// www.who.int/malaria/docs/protocol WHO. pdf.Accessed June 6, 2012.

[18] Naqvi R, Akhtar F, Ahmed E et al. Malarial Acute Kidney injury: 25

[19] years experience from a centre in Endemic region. BJMMR 2016; 12 (6): 16.

[20] Singh SP, Singh R, Ahmed N. A comparative study of complications of vivax and falciparum malaria in Dehdradun. Int J Res Med Sci 2014; 2 (1): 117-21.

[21] Sitprijia V. Nephropathy in falciparum malaria. Kidney Int 1988; 34: 867-77. 
[22] Kyes S, Horrocks P, Newbold C. Antigenic variation at infected red cells surface in malaria. Ann Rev Microbil 2001; 55: 673-707.

[23] Pongponratan E, Riganti E, Punpoowong BN et al. Microvascular sequestration of parasitised erythrocytes in human falciparum malaria: A pathological study. Am J Trop Med Hyg 1991; 44: 168-75.

[24] Saharan S, Kohli V, Lodha R et al. Thrombotic microangiopathy associated with Plasmodium vivax malaria. Paediatr Nephrolo 2009; 24: 523-4.

[25] Sharma J, Bharadhawa K, Shah K et al. Plamodium vivax malaria presenting as haemolytic uraemic syndrome. Indian J Pediatr 1993; 30: 369-71.

[26] Shukla VS, Singh RG, Rathore SS et al. Outcome of malaria associated acute kidney injury: a prospective study from a single centre. Renal Failure 2013; 35: 6, 801-5.

[27] Kocher DK, Singh P, Agarwal P et al. Malarial hepatitis. J Assoc Phys Ind 2003; 51: 1069-72.

[28] Kochar DK, Kaswan K, Kochar SK et al. A comparative study of regression of jaundice in patients of malaria and viral hepatitis. J Vector Borne Dis 2006; 43: 123-9.

[29] Kaushik R, Kaushik RM, Makkara R et al. Plasmodium vivax malaria complicated by acute kidney injury: experience at a referral hospital in Uttarakhand. India Trans R Soc Trop Med Hyg 2013; 107 (3): 188-94.

[30] Helbrok R, Dent W, Nacher M et al. Use of Multi Organ Dysfunction score to discriminate different levels of severity in severe and complicated Plasmodium falciparum malaria. Am J Top Med Hyg 2005; 72 (2): 150-4.
[31] Khan R, Quaiser S, Haque SF. Malarial acute Kidney injury: Prognostic markers. Ann Trop Med Public Health 2013; 6: 280-4.

[32] Win KKYK,Thanachartwet V,Wattanagoon Y et al. Factors associated with severe falciparum malaria. Southeast Asian J Trop Med Public Health 2012; 43 (5): 1071-9.

[33] Zewdu W. Acute renal failure in Addis Abada, Ethiopia: A prospective study of 136 patients. Ethio Med J 1994; 32: 79-87.

[34] Sarkar D, Ray S, Saha M et al.Talukdar A, Clinico laboratory profile of severe Plasmodium vivax in tertiary care centre in Kokata. Trop Parasitol 2013; 3: 53-7.

[35] Trong TT, Phk NH, Vinh $\mathrm{H}$ et al. Acute renal failure in patients with severe falciparum malaria. Clin Infect Dis 1992; 15: 874-80.

\section{AUTHORS}

First Author - Prashant S.Hiwale, Department of General Medicine, Deben Mahato Hospital and Government Medical College, prashanthiwale21@gmail.com

Second Author - P.K.Mukherjee, Department of General Medicine, Deben Mahato Hospital and Government Medical College 